\title{
Automotive Aerodynamics Analysis Using Two Commonly Used Commercial Software
}

\author{
Adil Loya', Ammar Iqbal'2, Muhammad Tauseef Nasir'1, Hasan Ali², \\ Muhammad Zia Ullah Khan', Muhammad Imran ${ }^{4}$
}

\footnotetext{
${ }^{1}$ Department of Mechatronics Engineering, PAF Karachi Institute of Economics and Technology, Karachi, Pakistan ${ }^{2}$ Department of Mechanical Engineering, COMSATS University Islamabad, Sahiwal, Pakistan

${ }^{3}$ Department of Mechanical Engineering, National University of Science and Technology, Islamabad, Pakistan ${ }^{4}$ Department of Mechanical Engineering, University of Engineering and Technology Lahore, Faisalabad, Pakistan Email: adil.loya@pafkiet.edu.pk, tauseef2007114@gmail.com, ammariqbal01@hotmail.com, hasanaliciit@gmail.com, engrimran23@gmail.com
}

How to cite this paper: Loya, A., Iqbal, A., Nasir, M.T., Ali, H., Khan, M.Z.U. and Imran, M. (2019) Automotive Aerodynamics Analysis Using Two Commonly Used Commercial Software. Engineering, 11, $22-32$.

https://doi.org/10.4236/eng.2019.111003

Received: October 27, 2018

Accepted: January 18, 2019

Published: January 21, 2019

Copyright $\odot 2019$ by author(s) and Scientific Research Publishing Inc. This work is licensed under the Creative Commons Attribution International License (CC BY 4.0).

http://creativecommons.org/licenses/by/4.0/ Open Access

\begin{abstract}
Aerodynamics analysis has become a mindset for high performance vehicles. This is because it provides valuable insight on a vehicle motion during different phases. There are vast varieties of software available like ANSYS Workbench, Star CCM+, Autodesk Simulation, SimFlow, FeatFlow, Autodesk Inventor etc. Amongst these softwares, Star CCM+ and ANSYS Workbench are the most widely used. Normally, it is observed that considerable users are confused in choosing the right software for CFD simulation because of a large variety of commercially available softwares. The present study provides comparative results to users of Computational Fluid Dynamics (CFD) with the driven case study. In the present case, authors chose the most commonly used CFD softwares, the ANSYS Workbench Fluent and the Star CCM+. Polyhedral meshing was applied on computer aided model of a car in both of these softwares. It has been found that coefficients of drag and lift achieved by aerodynamic analysis of a car are in a small marginal approximation between both ANSYS Workbench Fluent and Star CCM+ softwares. In the case of Star $\mathrm{CCM}+, C_{D}$ was around 0.261 and $C_{L}$ was 0.07 ; however, in the case of ANSYS Workbench Fluent approximations were found to be 0.271 for $C_{D}$ and 0.05 for $C_{L}$.
\end{abstract}

\section{Keywords}

CATIA, CFD, ANSYS Workbench Fluent, Star CCM+, Shear Stress Transport (SST), k-Omega 


\section{Introduction}

Aerodynamics plays a key role in the design process of a car. There are three types of air flows for a car. The first is air flow around the body of a car; the second is air flow through the internal car parts such as radiator, engine etc. and the third is the air flow through the passenger compartment. In our case, the external flow around the upper body of the car is analyzed.

The most important parameter in vehicle aerodynamics is the drag force which directly effects the fuel economy. However, it is difficult to solve the complicated partial differential equations which govern the fluid mechanics problems. In this modern era of computers, it has become possible to estimate the solutions of such complex problems using numerical techniques. These techniques involve the discretization of partial differential equations and their numerical solutions for the given input data. This whole process is the subject of CFD.

Fuel consumption due to the aerodynamic drag is more than half of the vehicle's energy. The drag reduction program is one of the most interesting approaches to provide this matter. Aerodynamic drag consists of two main components; skin friction drag dependent on vehicle geometry [1] due to the boundary layer separation from rare window surface and other is wake region that is formed behind the vehicle [2] [3].

The location of separation determines the size of wake region and thus it determines the value of aerodynamic drag.

The aerodynamic drag of road vehicle is responsible for large part of fuel consumption and contributes up to $50 \%$ of total vehicle fuel consumed at highway speeds [4].

This paper introduces the analysis of the aerodynamics drag and downforces on a commercial car designed for comparing two most popular softwares in aerodynamics industry. The reason for doing this is straightforward by carrying out this comparison. One can derive the conclusion that which software is the best to produce results with respect to aerodynamics drag and visualization. Moreover, researchers and industries are more often seen using Star CCM+ for aerodynamic simulations rather than ANSYS Workbench Fluent. Academia is using fluent for basic learning. However, which one is better for CFD simulations, is a question of concern around many researchers and industries.

The aim of this research is to provide a comparative solution between the two softwares so that an aerodynamicist can use the best software available for them in the market.

\subsection{Aerodynamic Forces}

Drag force opposes the motion of the car in which it is traveling. This ultimately affects performance of the car, fuel economy as well as results in greater power requirement [1]. The drag force is calculated by Equation (1.1) [5]:

$$
F_{D}=\frac{1}{2} \rho V^{2} C_{D} A
$$


where $F_{D}=\operatorname{drag}$ force $(\mathrm{N}), C_{D}=$ coefficient of drag, $A=$ frontal area $\left(\mathrm{m}^{2}\right), \rho=$ density of air $\left(\mathrm{kg} / \mathrm{m}^{3}\right), V=$ velocity of vehicle $(\mathrm{m} / \mathrm{s})$.

With the Drag force, there is one more component of the force called the Lift force or downforce which tends to keep vehicle attached to the ground and reduce friction between tyres and the road. If this lift is altered it causes car to wobble. This means combination of these two forces effects the stability and handling of the car [6]. Lift force plays a significant role in the aerodynamic optimization of the car. The lift force is calculated by Equation (1.2) [5]:

$$
F_{L}=\frac{1}{2} \rho V^{2} C_{L} A
$$

where $F_{L}=$ lift force $(\mathrm{N}), C_{L}=$ coefficient of lift, $A=$ frontal area $\left(\mathrm{m}^{2}\right), \rho=$ density of air $\left(\mathrm{kg} / \mathrm{m}^{3}\right), V=$ velocity of vehicle $(\mathrm{m} / \mathrm{s})$.

\subsection{Computational Fluid Dynamics (CFD)}

CFD is used extensively in industry to measure multiple parameters related to fluid dynamics. Laminar simulations can also be used depending on the application. The main advantage of using CFD is the fact that a whole team does not need to set-up the simulation and more parameters can be monitored simultaneously. Furthermore, by using CFD, internal flow analysis is also possible which is difficult to carry out using experimental methods and obtain reliable results. CFD is a cost-effective method for analyzing aerodynamics of an initial design concept [7]. Depending on the domain and meshing size, sometimes supercomputers are required to run simulations because they have multiple RAMs and processors for conducting high end CFD simulations on complex geometry within a reasonable timeframe. Fluids (gasses and liquids) are governed by partial differential equations that represent the general laws of conservation of mass, momentum, and energy [8].

The derivation of conservation of mass is dependent upon principle of mass balance within fluid element and it is expressed by Equation (1.3) [9].

$$
\frac{\partial \rho}{d t}+\nabla \times(\rho \times v)=0
$$

where $\frac{\partial \rho}{d t}$ with derivation of density with time change and $\nabla \times(\rho \times v)$ is time rate of change of volume of moving fluid.

The momentum equations in the $x, y$ and $z$ axes respectively expressed by Equation (1.4)

$$
\begin{aligned}
& \frac{\partial(\rho u)}{\partial t}+\nabla \times(\rho u V)=-\frac{\partial p}{\partial x}+\frac{\partial \tau_{x x}}{\partial x}+\frac{\partial \tau_{y x}}{\partial y}+\frac{\partial \tau_{z x}}{\partial z}+\rho f_{x} \\
& \frac{\partial(\rho v)}{\partial t}+\nabla \times(\rho v V)=-\frac{\partial p}{\partial y}+\frac{\partial \tau_{x y}}{\partial x}+\frac{\partial \tau_{y y}}{\partial y}+\frac{\partial \tau_{z y}}{\partial z}+\rho f_{y} \\
& \frac{\partial(\rho w)}{\partial t}+\nabla \times(\rho w V)=-\frac{\partial p}{\partial z}+\frac{\partial \tau_{x z}}{\partial x}+\frac{\partial \tau_{y z}}{\partial y}+\frac{\partial \tau_{z z}}{\partial z}+\rho f_{z}
\end{aligned}
$$


Energy equations used were derived by Navier Stokes which is depending upon first law of thermodynamics. The derivation for conservation of energy on a finite fluid element consists of one equation. This is expressed by Equation (1.5).

$$
\begin{aligned}
& \frac{\partial}{\partial t}\left[\rho\left(e+\frac{V^{2}}{2}\right)\right]+\nabla \times\left[\rho\left(e+\frac{V^{2}}{2}\right) V\right] \\
& =\rho \dot{q}+\frac{\partial}{\partial x}\left(k \frac{\partial T}{\partial x}\right)+\frac{\partial}{\partial y}\left(k \frac{\partial T}{\partial y}\right)+\frac{\partial}{\partial z}\left(k \frac{\partial T}{\partial z}\right) \\
& \quad-\frac{\partial(u p)}{\partial x}-\frac{\partial(v p)}{\partial y}-\frac{\partial(w p)}{\partial z}+\frac{\partial\left(u \tau_{x x}\right)}{\partial x}+\frac{\partial\left(u \tau_{y x}\right)}{\partial y} \\
& +\frac{\partial\left(u \tau_{z x}\right)}{\partial z}+\frac{\partial\left(v \tau_{x y}\right)}{\partial x}+\frac{\partial\left(v \tau_{y y}\right)}{\partial y}+\frac{\partial\left(v \tau_{z y}\right)}{\partial z} \\
& +\frac{\partial\left(w \tau_{x z}\right)}{\partial x}+\frac{\partial\left(w \tau_{y z}\right)}{\partial y}+\frac{\partial\left(w \tau_{z z}\right)}{\partial z}+\rho f \times V
\end{aligned}
$$

CFD softwares give an accurate and deep understanding of the patterns of the fluid flow that are difficult to predict with regular experiments, as they are costly and sometimes laborious to conduct.

This study consists of the CFD simulation of Upper Body of DICE car. The car was designed using CATIA and then CFD simulation softwares were used for aerodynamics analysis.

\subsection{CFD Working}

CFD utilizes mathematical equations and tools to solve aerodynamic problems. Steps for conducting CFD calculations are:

- Data entry into the computer.

- Mathematical Modelling.

- Interpretation of the modelling into computational algorithms and codes.

- Computer aided calculations.

- Data acquisition.

- Post calculation analysis.

Furthermore, the schematic design in Figure 1 illustrates the steps followed for conducting CFD calculations/simulation.

\section{Materials and Method}

Surface modelling of a car geometry was carried out on CATIA software. Then iges file was imported in ANSYS Workbench i.e. Fluent as well as Star CCM+ for simulation.

The base size of mesh was set to be $0.4 \mathrm{~m}$ in both softwares. Meshing was applied to the car model on Star CCM+ using polyhedral cells as shown in Figure 2 and same was adopted in ANSYS Workbench as shown in Figure 3.

Flow computation in ANSYS as well as in Star CCM+ was accomplished using Shear Stress Transport (SST) k-omega equation model. The SST k-omega model 


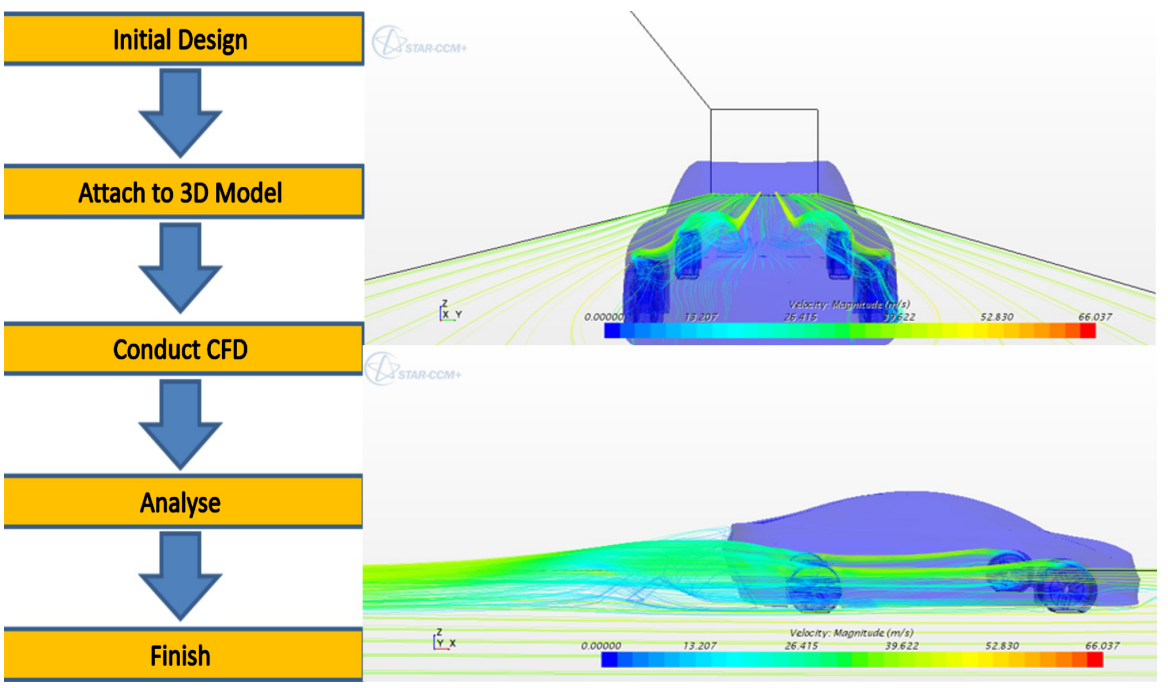

Figure 1. Schematic view of procedure followed for conducted CFD.

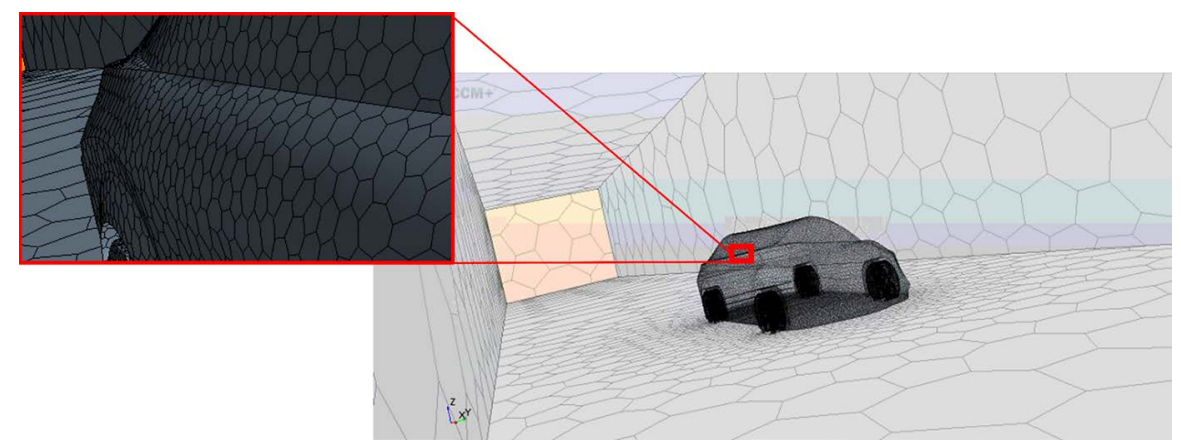

Figure 2. Meshing in Star CCM+.

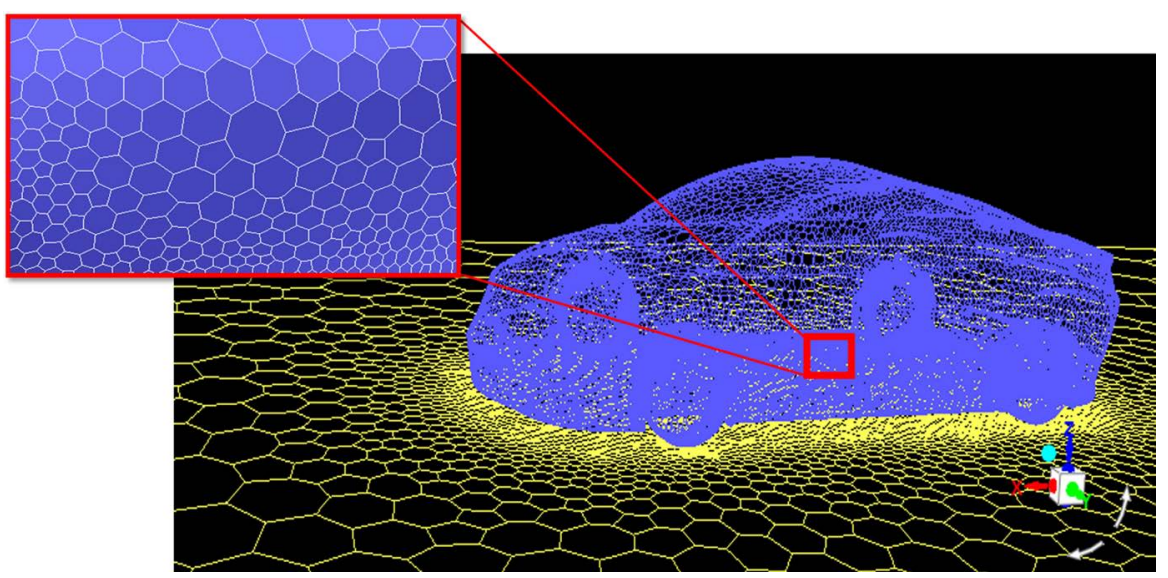

Figure 3. Meshing in ANSYS Workbench.

helps in determining the flow effect near the boundary wall region and it helps in examining the flow separation in detail. This helps user for analyzing properties of flow at low Reynolds number with better accuracy, as was investigated by [10]. Table 1 represents the settings applied for conducting simulation on the model used in this study. 


\section{Results}

The outcomes of this study have been gathered in this section. Table 2 represents results of coefficients of drag and lift.

After convergence of solution in ANSYS Workbench Fluent, drag coefficient and lift coefficient were calculated as 0.271 and 0.05 as shown in Figure 4 and Figure 5 respectively.

On the other hand, after convergence of solution in Star CCM+, the drag coefficient and lift coefficient were computed as 0.261 and 0.07 as shown in Figure 4 and Figure 5 respectively. The difference between drag coefficients of both softwares are due to slight variation in frontal areas.

Residual graphs of Star CCM+ and ANSYS Workbench Fluent, shown in Figure 6 and Figure 7 respectively indicated the solutions converged.

High static pressure was observed at front side of a car on both softwares as shown in Figure 8 and Figure 9. Nevertheless, it is necessary to maintain low static pressure on the roof of a car, for this lowering of car nose and optimizing their fenders was considered using designing phase [11] [12]. Due to which, high velocities on a car roof were produced as shown in Figure 10 and Figure 11.

Table 1. Attributes settings for CFD over a car.

\begin{tabular}{ccc}
\hline Items & ANSYS Workbench Fluent & Star CCM+ \\
\hline Meshing & Polyhedral & Polyhedral \\
Convergence & Residuals 10e-3 & Residual 10e-3 \\
Frontal Area & $1.929 \mathrm{~m}^{2}$ & $1.929 \mathrm{~m}^{2}$ \\
Density & $1.225 \mathrm{~kg} / \mathrm{m}^{3}$ & $1.225 \mathrm{~kg} / \mathrm{m}^{3}$ \\
Velocity & $47.22 \mathrm{~m} / \mathrm{s}$ & $47.22 \mathrm{~m} / \mathrm{s}$ \\
Solution & Coupled & Coupled \\
Model & Shear Stress Transport (SST) k-omega & Shear Stress Transport (SST) k-omega
\end{tabular}

Table 2. Results of coefficients of drag and lift of a car.

\begin{tabular}{ccc}
\hline Items & ANSYS Workbench Fluent & Star CCM+ \\
\hline$C_{D}$ & 0.271 & 0.261 \\
$C_{L}$ & 0.05 & 0.07 \\
\hline
\end{tabular}

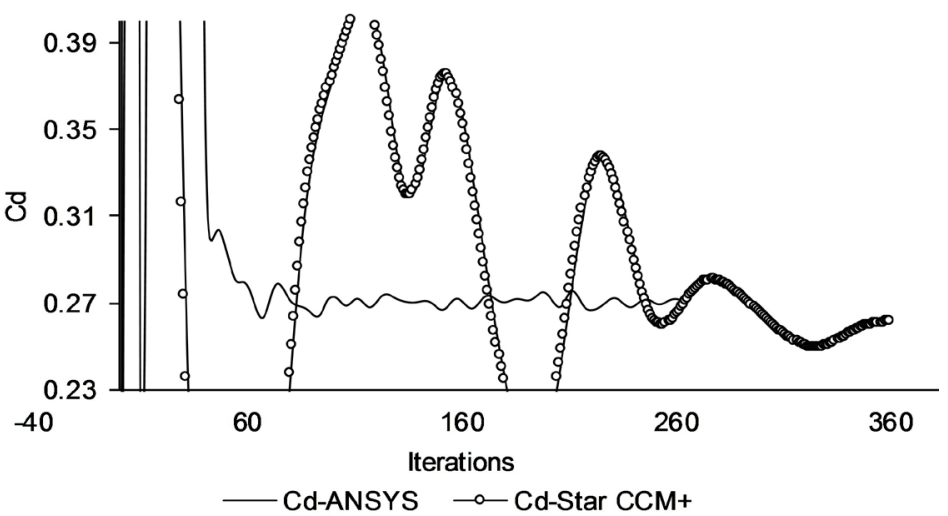

Figure 4. Superimposed results of Star CCM+ and ANSYS for $C_{D}$ at $170 \mathrm{~km} / \mathrm{h}$. 


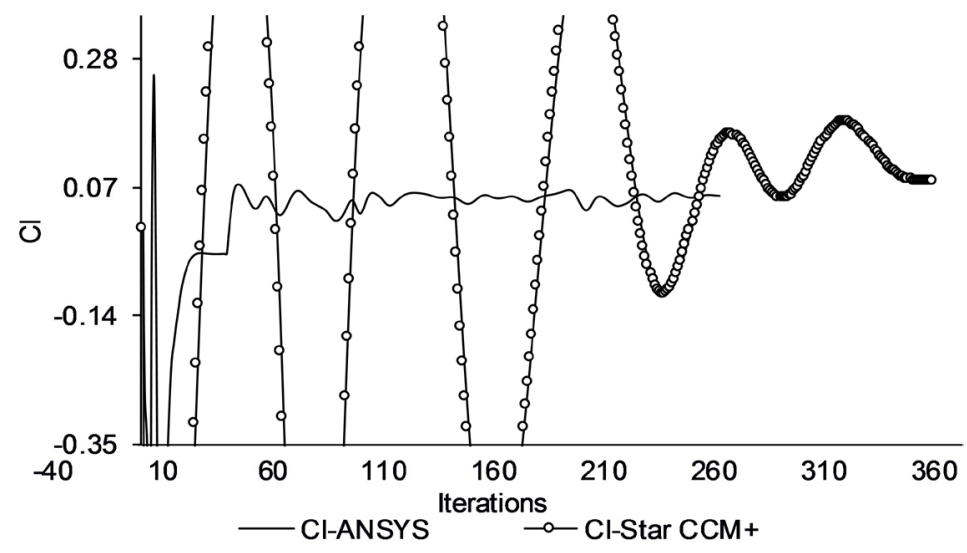

Figure 5. Superimposed results of Star CCM+ and ANSYS for $C_{L}$ at $170 \mathrm{~km} / \mathrm{h}$.

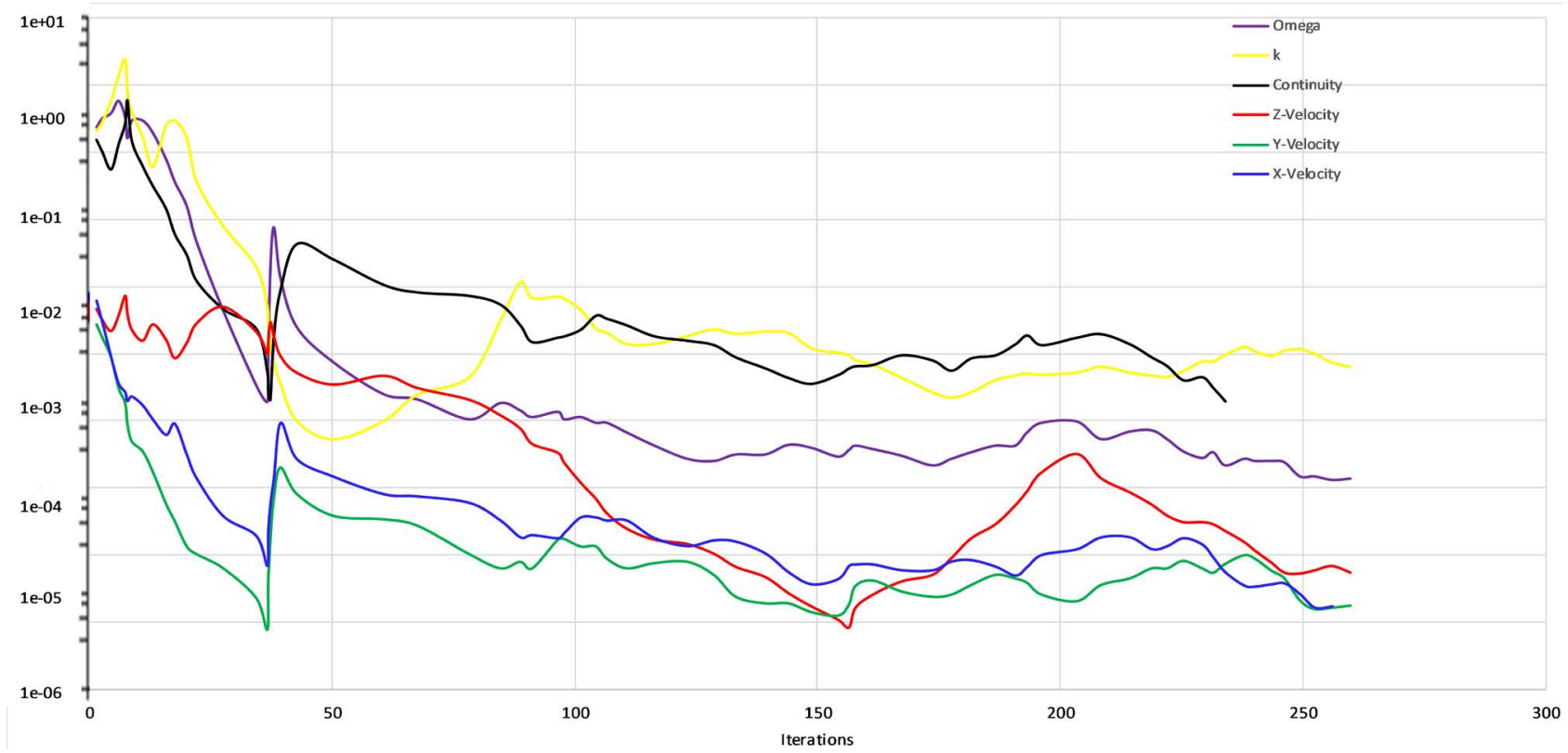

Figure 6. Residual graph of ANSYS Workbench Fluent.

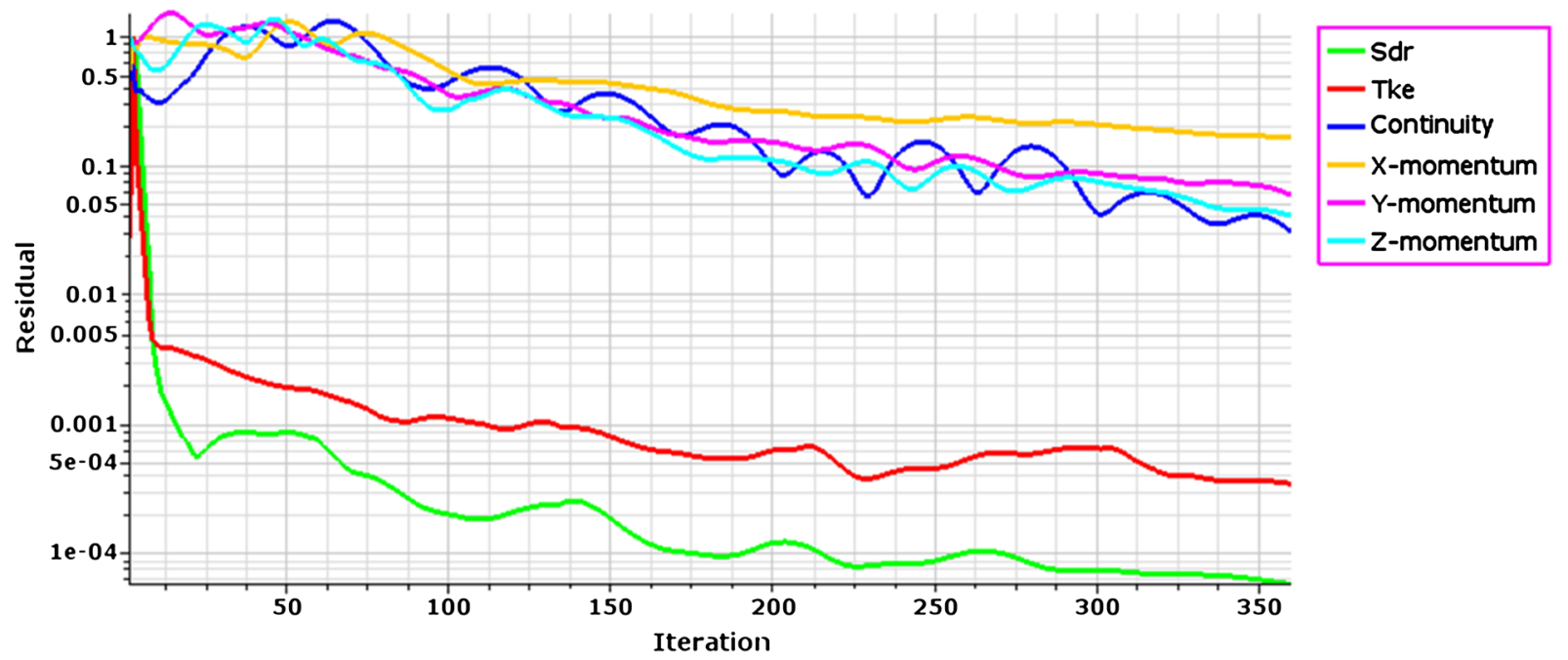

Figure 7. Residual graph of Star CCM+. 


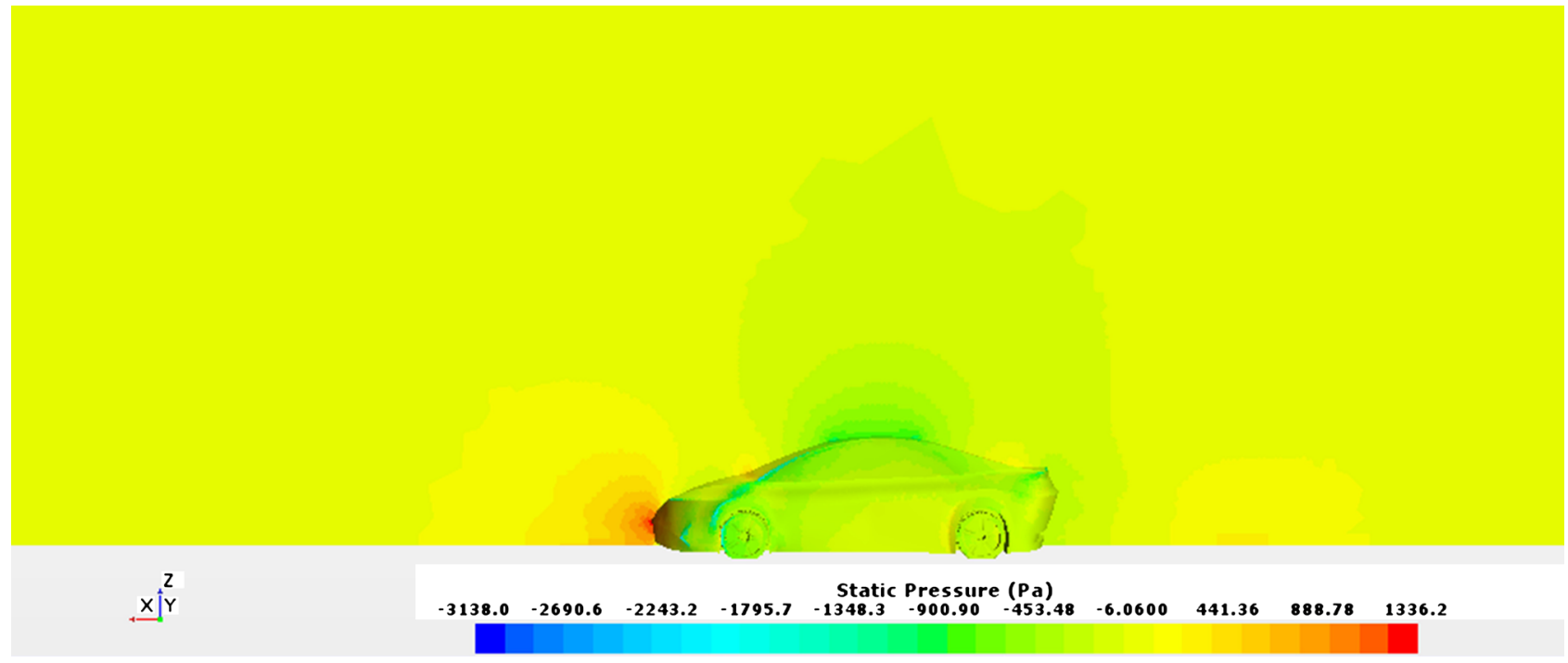

Figure 8. Static pressure of Star CCM+.

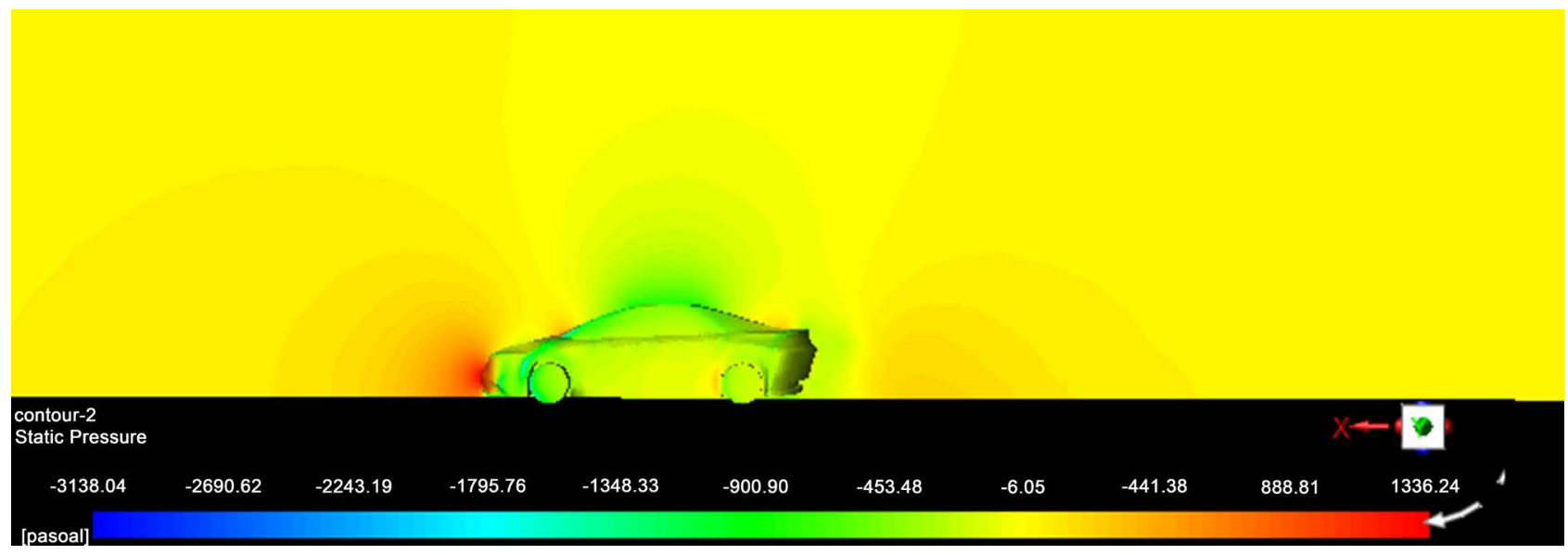

Figure 9. Static pressure of ANSYS Workbench.

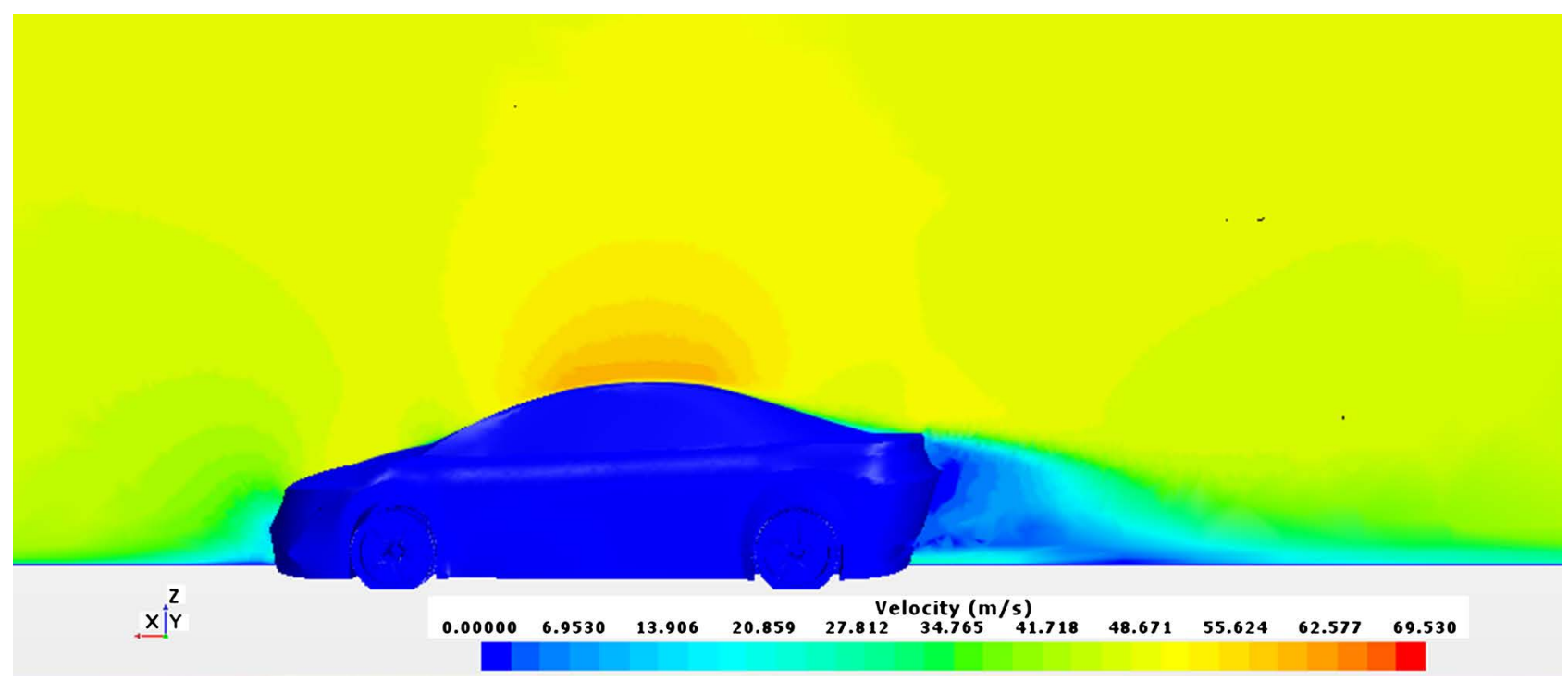

Figure 10. Velocity of Star CCM+. 


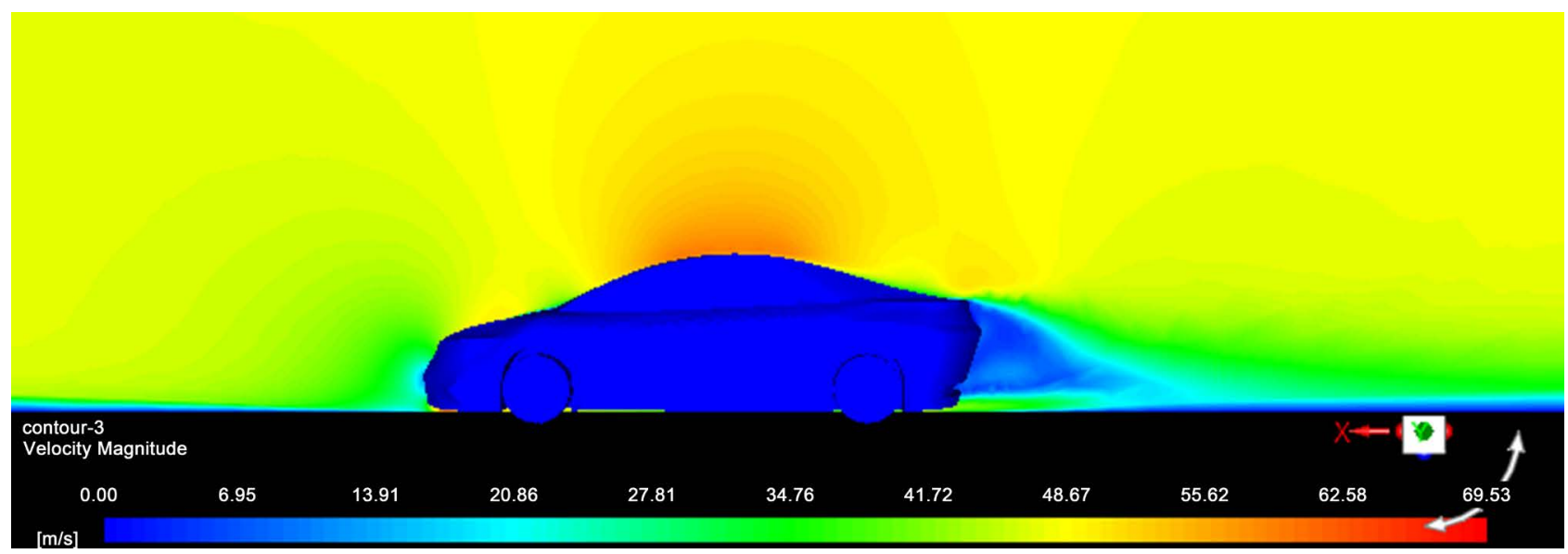

Figure 11. Velocity of ANSYS Workbench.

\section{Discussion}

Two different CFD softwares were used for simulation of fluid dynamics over a car. The model's meshing and physical conditions on both the softwares were set to be identical as much as possible. However, the computation of mesh on different softwares used diverse algorithms to generate mesh over a body, by doing so it produced inconsistencies, when the results were compared.

Nonetheless, the meshing base size and prism layer were established in similar way for achieving the concurrent results. As far physical conditions are concerned, they were applied in a way that it resembles in both the softwares. By taking care of pre-processing steps of CFD analysis, solver generated high accuracies between the number of iterations required to solve the flow dynamics over the vehicle. The post-processing results were displayed simultaneously for the velocity contours as shown in Figure 10 and Figure 11, and the pressure contours as shown in Figure 8 and Figure 9. Moreover, plotted results of $C_{D}$ and $C_{L}$ with number of iterations represented similar trend of decay as shown in Figure 4 and Figure 5 respectively.

Moreover, the boundary layer detachment was observed behind the car was due to the edge of the car trunk causing the occurrence of separation. That is why, when the values of both simulations were compared, it was found that the Star CMM+ results were better, however, there was a sense of non-impregnable approach as the decaying trend of the $C_{D}$ and $C_{L}$ with number of iterations demonstrated less fluctuation in case of ANSYS Workbench Fluent.

SST k-omega model was considered for both softwares as it helps in merging the k-Epsilon with k-Omega, however, it is known that k-Epsilon depicts the turbulence generation, though, standard k-Omega is more concerned about the flow attachment [10] i.e. more into the boundary layer function analysis. It is hard to define flow by just considering boundary layer flow functions, as it creates ambiguity of results, as the conditions of car aerodynamics are not well defined after the detachment process of boundary layer i.e. the wake region. This was also investigated by [10] that as the boundary layer detachment happens the 
K-Omega model deviates and is not fruitful in computing flow behind the car, for demonstrating proper wake generation. The wake generation can easily be understood by the designs of latest cars having new downforce devices to optimize rear flow of car. The drag caused by wake makes the car performance to decrease and in turn making the car less cost effective.

\section{Conclusions}

The study has established comparisons between results of ANSYS Workbench Fluent and Star CCM+. In comparison, author's focused on drag and lift coefficient of a car with models pertaining to SST k-omega in ANSYS Workbench Fluent and Star CCM+. It was observed that the results were considerably accurate with a percentage error of $3 \%-4 \%$ in drag coefficients, while it was estimate to be around $2 \%-30 \%$ for the lift coefficient. This error is most likely appeared due to back end calculations during different equations that were used by two different softwares. The lift coefficient error was considerably high; this was expected, since rims used is Star CCM+ which were different than the one used in ANSYS Workbench, thereby causing the downforces to decrease and also no vortexes are generated close to rims in the case of ANSYS Workbench.

Moreover, the discrepancies might also be caused by importing wizard of Star $\mathrm{CCM}+$ which has different import methodology than that of ANSYS Workbench. In Star CCM+ the software asks initially regarding the smoothness of edges; however, this was not carried out using ANSYS Workbench. To the best of authors' knowledge, this is the first study of its kind. Hence this study seems to be an opening gate for researchers to select a correct software for conducting the analysis of aerodynamics around a car.

\section{Conflicts of Interest}

The authors declare no conflicts of interest regarding the publication of this paper.

\section{References}

[1] Smith, C. (1978) Tune to Win. Aero Publishers, Fallbrook.

[2] Hucho, W.-H. (2013) Aerodynamics of Road Vehicles: From Fluid Mechanics to Vehicle Engineering. Elsevier, Amsterdam.

[3] Katz, J. and Bentley, R. (2006) Aerodynamics of Race Cars. Annual View of Fluid Mechanics, 38, 27-63. https://doi.org/10.1146/annurev.fluid.38.050304.092016

[4] Sudin, M.N., Abdullah, M.A., Ramli, F.R., Musthafah, M.T. and Shamsudin, S.A. (2014) Review of Research on Vehicles Aerodynamic Drag Reduction Methods. International Journal of Mechanical and Mechatronics Engineering, 14, 35-47.

[5] O’Rourke, B. (1990) The Uses of Composite Materials in the Design and Manufacture of Formula 1 Racing Cars. Proceedings of the Institution of Mechanical Engineers, Part D: Journal of Automobile Engineering, 204, 41-48. https://doi.org/10.1243/PIME_PROC_1990_204_131_02

[6] Howell, J. and Le Good, G. (1999) The Influence of Aerodynamic Lift on High 
Speed Stability. SAE Technical Paper 0148-7191.

[7] Mason, W.H., Knill, D.L., Giunta, A.A., Grossman, B., Watson, L.T. and Haftka, R.T. (1998) Getting the Full Benefits of CFD in Conceptual Design. 16th AIAA Applied Aerodynamics Conference, Albuquerque, NM, 15-18 June 1998, 2513. https://doi.org/10.2514/6.1998-2513

[8] Barnes, D.I. (2015) Understanding Pulverised Coal Biomass and Waste Combustion-A Brief Overview. Applied Thermal Engineering, 74, 89-95. https://doi.org/10.1016/j.applthermaleng.2014.01.057

[9] Anderson Jr., J.D. (2010) Fundamentals of Aerodynamics. 5th Edition, Chapter \# 02, Momentum Equation, 127.

[10] Menter, F.R. (1994) Two-Equation Eddy-Viscosity Turbulence Models for Engineering Applications. AIAA Journal, 32, 1598-1605. https://doi.org/10.2514/3.12149

[11] Motors, G. (1979) More Efficient Big Cars. Hearst Magazines, 152.

[12] Marklund, J. (2013) Under-Body and Diffuser Flows of Passenger Vehicles. Chalmers University of Technology, Göteborg. 